\title{
O ESTÁGIO CURRICULAR NA FORMAÇÃO INICIAL DE PROFESSORES: UM RECORTE DE PRODUÇÕES ${ }^{1}$
}

\author{
Alvanize Valente Fernandes Ferenc ${ }^{2}$ \\ Caio Corrêa Derossi ${ }^{3}$
}

\begin{abstract}
RESUMO: Este trabalho reflete sobre o estágio curricular no âmbito da formação inicial de professores. Para tanto, explora as produções científicas dos Congressos Estaduais Paulistas sobre Formação de Educadores (CEPFE) - 2009 a 2018. A partir dos anais destes eventos, buscou-se, a priori, mapear as produções veiculadas no primeiro eixo temático - "Políticas e Práticas de formação inicial de professores da educação básica", para a posteriori, analisar os trabalhos que tinham como objeto o estágio. Na construção do texto é apresentado um panorama bibliográfico sobre o campo da formação inicial de professores e, em seguida, procede-se à organização das produções selecionadas. De forma geral, em todos os trabalhos analisados, o estágio é entendido como espaço de aproximação dos cotidianos dinâmicos que permeiam a profissão docente. Logo, após o reconhecimento deste cenário, as práticas de ensino, os desafios e as potencialidades do ensinar, inseridas as idiossincrasias de cada campo, são mais bem refletidas e situadas.
\end{abstract}

Palavras-chave: Formação de professores. Estágio supervisionado. Integração universidade-escola.

\section{THE CURRICULAR INTERNSHIP IN INITIAL TEACHER TRAINING: A CUT OF PRODUCTIONS}

ABSTRACT: This work reflects on the curricular internship in the context of initial teacher training. To this end, it explores the scientific productions of the São Paulo

\footnotetext{
${ }^{1}$ Cabe ressaltar que Azevedo e Ferenc (2012) já publicizaram em evento um estudo que se debruçou sobre os dois primeiros congressos citados. Portanto, o presente texto atualiza e compara as perspectivas do trabalho anterior.

2 Pós-doutora pela FPCE da Universidade do Porto, Portugal (2020) e pela FaE/UFMG (2014). Doutora em Educação pela Universidade Federal de São Carlos (2005), com estágio de Doutoramento na Universidade do Porto, Portugal. Atualmente, é Professora Associada da Universidade Federal de Viçosa. E-mail: avalenteferenc@gmail.com.

3 Mestre pelo Programa de Pós-Graduação em Educação da Universidade Federal de Viçosa (UFV) (2019). Graduado (2018) em Licenciatura em História pela Universidade Federal de Viçosa. E-mail: derossi.caio@gmail.com
} 
State Congresses on Educator Training (CEPFE) - 2009 to 2018. From the annals of these events, it was sought, a priori, to map the productions conveyed in the first thematic axis - "Policies and Practices of initial training of teachers of basic education" -, to a posteriori, analyze the works that had as object the internship. In the construction of the text, a bibliographic overview of the field of initial teacher education is presented and then the selected productions are organized. In general, in all the studies analyzed, the internship is understood as a space to approach the dynamic daily life that permeates the teaching profession. Therefore, after recognizing this scenario, teaching practices, challenges and teaching potential, inserted in the idiosyncrasies of each field, are better reflected and situated.

Keywords: Teacher education. Supervised internship. University-school integration.

\section{LA PRÁCTICA CURRICULAR EN FORMACIÓN INICIAL DE PROFESORES: UN CORTE DE PRODUCCIONES}

RESUMEN: Este trabajo reflexiona sobre la pasantía curricular en el contexto de la formación inicial del profesorado. Con este fin, explora las producciones científicas de los Congresos del Estado de São Paulo sobre Formación de Educadores (CEPFE)2009 a 2018. A partir de los anales de estos eventos, buscamos a priori mapear las producciones transmitidas en el primer eje temático - "Políticas y prácticas de formación inicial de docentes de educación básica" -, a posteriori, analizar los trabajos que tenían como objeto la pasantía. En la construcción del texto, se presenta una descripción bibliográfica del campo de la formación inicial del profesorado y luego se organizan las producciones seleccionadas. En general, en todos los estudios analizados, la pasantía se entiende como un espacio para abordar la dinámica vida cotidiana que impregna la profesión docente. Por lo tanto, después de reconocer este escenario, las prácticas de enseñanza, los desafíos y el potencial de enseñanza, insertados en las idiosincrasias de cada campo, se reflejan y sitúan mejor.

Palabras clave: Formación de professores. Pasantía supervisada. Integración universidad-escuela.

\section{Introdução}

O presente artigo se inscreve no campo da formação de professores e apresenta uma reflexão sobre o estágio curricular no âmbito da formação inicial docente. Explora os trabalhos apresentados entre os anos de 2009-2018, nos Congressos Estaduais 
Paulistas de Formação de Educadores (CEPFE), promovido pela Universidade Estadual Paulista "Júlio de Mesquita Filho" (UNESP). A lacônica exposição visa corroborar para o debate sobre a formação docente e complementar o trabalho, de Azevedo e Ferenc (2011; 2012), já publicizado em congresso.

Essa temática vem, há muito, sendo discutida nas universidades, especificamente nos cursos de licenciaturas, mas ainda apresenta muitos desafios em se constituir em um lugar de sínteses, e interlocuções institucionais, sobre processos de aprendizagem e de constituição de saberes sobre a profissão, seja no interior das universidades, seja nas escolas de educação básica. O estágio curricular pode se apresentar como um dos caminhos de aproximação entre essas instâncias educativas, assumindo o lugar de mediador entre o conhecimento produzido e socializado nesses diferentes espaços.

Pimenta e Lima (2004) entendem que a formação profissional, independente da área de atuação, tem uma componente estruturação prática muito forte, já que é implicado com o fazer, com a ação. Neste sentido, as autoras destacam o estágio como elemento que articula, de um lado, a formação teórica e reflexiva que o subsidia, e do outro lado, as práticas dos professores. Atinente a tal colocação, a pergunta mobilizadora, que figura no pano de fundo do trabalho, refere-se a como o estágio é apresentado nas produções oriundas de instituições de formação docente.

Neste sentido, Azevedo e Ferenc (2011) tiveram como escopo analisar o estágio na formação inicial de professores, a partir das comunicações apresentadas no X e XI Congressos Estaduais Paulistas sobre Formação de Educadores, nos anos de 2009 e 2011, respectivamente. Cabe destacar que a escolha do CEPFE como fonte para tal texto, deveu-se a reputada história de contribuição oferecida aos estudos de formação de professores e suas ressonâncias nacional e internacional. Os eventos, como os próximos, citados a posteriori, ocorreram no município de Águas de Lindóia. Portanto, a partir do livro eletrônico e do CD-ROM, que continham as pesquisas comunicadas, a partir de análises que evidenciaram os eixos temáticos, os títulos e os resumos das apresentações, expõem-se as análises.

Levando em consideração este ponto de partida, o atual trabalho propõe uma análise mais holística, a partir da ampliação das fontes, a saber, os anais do XII, XIII e XIV CEPFE'S. 
Em dois universos totais de 354 e 680 trabalhos publicados no CEPFE em 2009 e 2011, Azevedo e Ferenc (2011) focalizaram as comunicações inscritas nos seguintes eixos: formação inicial e continuada de professores para a educação básica e projetos e práticas de formação de professores. A partir deste recorte, foram selecionados 10 trabalhos relativos ao X CEPFE e 16 trabalhos da edição seguinte do congresso, totalizando 26 comunicações. Para além do título e do resumo que foram analisados, como supracitado, com a finalidade de mapear aqueles referentes à temática do estágio na formação inicial, aspectos como a instituição, a quantidade de trabalhos e os cursos que eram vinculados, foram outros aspectos analíticos observados.

Dando seguimento a este trabalho, propõe-se a análise de pesquisas relacionadas à temática enfocada, circunscrito ao eixo temático Políticas e Práticas de formação inicial de professores da educação básica. Portanto, no XII CEPFE, em um universo de 281 trabalhos, foram selecionados 31. No XIII Congresso, de 214 trabalhos, 26 tratavam do tema escolhido. E no XIV Congresso, de 186 trabalhos do eixo estudado, 10 referiam-se a proposta analisada. Os mesmos critérios de frequência, curso e instituição também foram inflexões para a pesquisa.

A proposição deste estudo foi a construção de um estado do conhecimento (ROMANOWSKI; ENS, 2006), que é um trabalho, que em dimensões de objeto e análise, mais pontuais, seleciona e organiza as produções acerca de um tema. Com isto, os precípuos reflexos, de acordo com as autoras, evidenciam as teorias, as abordagens e as lacunas estudadas ou não, pelos pesquisadores do campo específico, suscitando assim um melhor debate e diretrizes para novas investigações.

Mesmo que o presente estudo não se configure como um estado da arte, ampliado e de análise verticalizada, acredita-se que ele possa oferecer sinais paradigmáticos e indiciosos acerca das perspectivas enfocadas para o estágio na formação inicial, uma vez que os congressos científicos, como os em voga no texto, são sintomáticos, vitrines das discussões acadêmicas e profissionais sobre a docência. Entretanto, reconhece-se óbices na prática deste tipo de pesquisa, já citados por Romanowski e Ens (2006), no que se refere a disponibilidade dos dados, as condições de trabalho docente e discente, ao uso de equipamentos e tecnologias, entre outros. Assume-se também que o campo dos eventos científicos é um espectro de percepção, 
entre tantos outros, que particularizam e dimensionam de formas distintas variados aspectos.

\section{O estágio como prática formadora}

Os debates sobre formação inicial de professores são marcados pelas inflexões entre os espaços escolar e universitário. Assim, entendendo a academia como produtora e formadora de conhecimentos docentes, uma pergunta constante incide sobre a ancoragem e a socialização de tais conhecimentos para/no ambiente escolar. Portanto, quais as relações das produções acadêmicas com as práticas pedagógicas das escolas? Não se trata de chancelar que todo o conhecimento obrigatoriamente tenha um produto prático, de aplicação imediata. Entretanto, quando analisamos esta situação, no exemplo o estágio supervisionado, notam-se dificuldades da socialização e da troca de saberes e de demandas entre estes dois espaços.

Pimenta e Lima (2004) apontam que o estágio, quando bem concebido e estruturado em termos de orientação e diálogo curricular, pode ser um instrumento de aproximação entre a escola e a universidade. Porém, as autoras destacam que, em alguns casos, a aproximação não ocorre, em função de uma supervalorização do saber acadêmico sobre o saber escolar ou vice-versa, configurando uma hierarquia de conhecimentos que não visa a mediação e a socialização.

Mas, Pimenta e Lima (2004, p. 140-141), mesmo com os desafios enfrentados que conduzem a uma desvalorização do estágio, reforçam que ele tem relação adstrita com "[...] à luta pela melhoria dos cursos de formação de professores, pela valorização do magistério e por uma escola de ensino fundamental e médio mais democrática. $[\ldots]^{\prime \prime}$.

Nesta direção, Nóvoa (1999, p. 119) elenca pontos que os cursos de formação inicial de professores preconizariam para os futuros professores:

1. Identificar-se a si próprio como professor e aos estilos de ensino que é capaz de utilizar, estudando o clima da turma e os efeitos que os referidos estilos produzem nos alunos.

2. Ser capaz de identificar os problemas de organização do trabalho na sala de aula, com vista a torná-lo produtivo. Os problemas de disciplina e de organização da classe são os mais agudos durante o primeiro ano de exercício da profissão. 
3. Ser capaz de resolver os problemas decorrentes das atividades de ensinoaprendizagem, procurando tornar acessíveis os conteúdos de ensino em cada um dos seus alunos.

Nóvoa (2007) entende que a formação do professor deva superar um modelo de hipervalorização teórica e buscar nos espaços das práticas, do trabalho e da escola, locais para a reflexão e a co-formação docente. Segundo o autor, os modelos que aproximavam o professor da futura realidade de trabalho, propondo elos entre a escola e a universidade, possibilita aos estudantes a condição de refletir, rever, repensar, analisar as suas ações e assim fomentar o desenvolvimento dos seus saberes profissionais.

Canário (2002) considera que a formação de professores é um exercício contínuo que se inicia com a formação inicial e que ela deve estar relacionada com a atuação profissional futura. Assim, a escola é espaço de aprendizagem profissional e a primeira formação, em decorrência disto, deve promover no aluno, o entendimento que as experiências no futuro espaço de trabalho, são, portanto, formativas.

$\mathrm{O}$ autor ainda propõe uma diferenciação entre qualificação, competência e formação. Apesar dos dois primeiros sintagmas serem utilizados como sinonímias do último, a qualificação é um processo de aquisição e acúmulo de conhecimentos, enquanto a competência é habilidade adquirida pelo exercício prático da função, e não em formação teórica.

Pensando na escola como espaço formativo para o professor, Canário (2002) considera como indispensável considerar e entender os aspectos de organização e de funcionamento da escola e das relações de trabalhos coletivo e individual, exercidos pelos participantes daquelas realidades. Assim, a formação continuada perpassa para este pesquisador, na necessidade de políticas públicas que, partindo da escola como eixo central, articulem o desenvolvimento dos licenciandos.

O reconhecimento do papel da escola como local de formação também é defendido por Nóvoa (2003). Entretanto, ele não nos encaminha para uma ação coadjuvante da universidade. Mas, sim, para uma proposta de relação entre os distintos espaços, já entendendo as conexões entre os aspectos teóricos e as vivências refletidas das experiências. Neste sentido, Nóvoa (2009) aponta para a participação dos professores experientes na formação dos licenciandos, para que o desenvolvimento profissional se dê de forma endógena a profissão e não de modo 
alheio ou estranho a ela. Quando os professores mais experientes colaboram com a formação dos mais novos, inicia-se segundo o autor, uma cultura da profissão, que concede aos profissionais e aos espaços, cotidianos e vivências, devidamente refletidos e criticados, um lugar de reconhecimento, na formação docente. Portanto, a defesa do autor é a construção do futuro professor no espaço interior da profissão, a escola e a sala de aula, garantindo que os professores da educação básica e universitários possam compor este complexo processo formativo.

Neste sentido, Ambrosetti e Ribeiro (2005) entendem a escola enquanto espaço de constante revisão e reconstrução das discussões sobre os processos de aprendizagem, de exercícios, de identidades e de socializações docentes. Damasceno e Monteiro (2005), citando Garcia (1999), acenam para a escola como espaço privilegiado para sediar a formação continuada e o desenvolvimento profissional dos professores. Pois, é na instituição escolar que os saberes práticos da docência se desenvolvem e, segundo as autoras, tais conhecimentos precisam ser valorizados e estudados, a partir de sua inserção em determinado contexto. Nogueira (2005) também aponta para uma formação coletiva, baseada em projetos e na partilha das vivências na escola, como caminho para os cursos de licenciatura. Mas um aspecto central na formação de professores é, emblematicamente, posto por Nóvoa (2019, p.6): "tornar-se professor [...] obriga a refletir sobre as dimensões pessoais, mas também sobre as dimensões coletivas do professorado. Não é possível aprender a profissão docente sem a presença, o apoio e a colaboração dos outros professores".

Pimenta, Christensen e Rinaldi (2005) colaboram com essa problematização ao destacarem a importância de se ouvir os professores da educação básica e os seus contextos, nos processos de formação continuada. Segundo as autoras, muitos docentes apontam que os planejamentos são verticalizados e que não os tem como participantes-autores. Em contrapartida, verifica-se resistências de participação e de colaboração de professores em alguns projetos formativos. Assim, pode-se complementar com o direcionamento de Oliveira e Freitas (2005), que a escola e a universidade devem manter uma relação de parceria, fomentando ações que valorizem a reflexão sobre a prática, em prol do futuro professor. Nesse sentido, Nóvoa (2019, p. 2) insiste "na necessidade de uma nova institucionalidade, juntando em triângulo as universidades, profissão docente e as escolas da rede". 
Assim, para Pimenta e Lima (2004) quando o estágio é bem desenvolvido, refletindo sobre as idiossincrasias e os contextos locais, ele é um importante formador para o futuro docente, já que no sentido da formação docente, Imbernón (2011) indica que mediante as transformações em tempo acelerado, ocorridas nas sociedades ocidentais, essa profissão não pode se manter em um modelo que conceba o professor como um agente que apenas transmite conhecimentos.

As instituições educativas precisam se aproveitar de tais mudanças e dos personagens sociais, para construir e modificar os processos de educar vigentes. Mas, como enfatiza Nóvoa (2019, p. 6),

Não se trata de convocar apenas as questões práticas ou a preparação profissional, no sentido técnico ou aplicado, mas de compreender a complexidade da profissão em todas as suas dimensões (teóricas, experienciais, culturais, políticas, ideológicas, simbólicas, etc.). [...].

Logo, a partir das relações evidenciadas por Imbernón (2011), por exemplo, as sociedades e, por conseguinte, a educação, vem se complexificando de forma crescente, trazendo assim, modificações e novas exigências ao professor e às instituições de ensino. Assim, diante da reflexão e assimilação dessas mudanças, o autor mostra que o tempo no qual vivemos é simbolizado pelo requerer de uma educação diferente, redefinida e refletida pela sociedade, mas principalmente, pelos profissionais e seus cursos formadores.

Nóvoa $(2019$, p. 6) defende que a escola, nos dias de hoje, está a passar por um "processo de metamorfose". O autor, insistindo no compromisso público com a educação, argumenta que o diagnóstico crítico que faz, sobre a educação e a escola, visa "reforçar e valorizar as dimensões profissionais, seja na formação inicial e continuada, seja num exercício da docência que só se completa através de um trabalho coletivo com os outros professores. [...]". E o estágio precisa ser pensando na composição dessa nova escola.

Assim, a partir de Pimenta e Lima (2004), considera-se que o estágio como elemento conector de teoria e prática, é um espaço fortuito para a pesquisa e para o desenvolvimento do futuro professor, desde o início de sua formação. Assim, o espaço do estágio torna-se, além de ser um elo dos cotidianos e práticas escolares, um ponto para a reflexão sobre o trabalho, atuação e dimensão coletiva do exercício docente, 
evidenciando uma composição feita pelas distintas aprendizagens ocorridas no período.

O estágio como reflexão da práxis possibilita aos alunos que ainda não exercem o magistério aprender com aqueles que já possuem experiência na atividade docente. No entanto, a discussão dessas experiências, de suas possibilidades, do porquê de darem certo ou não, configura o passo adiante à simples experiência [...]. (PIMENTA; LIMA, 2004, p. 103).

\section{O estágio nos Congressos de Formação de Professores}

Como explicitado, o presente texto retoma a análise realizada por Azevedo e Ferenc (2011) e estende o uso de fontes, a partir dos trabalhos comunicados no mesmo Congresso, dentre os quais, encontram-se comunicações de pesquisas e relatos de experiências, que eram as categorias em que poderiam ser inscritos.

$O$ trabalho de avaliação do $X$ e do XI CEPFE foi realizado através do livro eletrônico e do CD-ROM com todos os textos apresentados no evento. Em um universo de 1034 trabalhos, dos eixos Formação inicial e continuada de professores para a educação básica e Projetos e práticas de formação de professores, foram selecionados 26 , sendo 10 do primeiro e 16 do segundo. No processo de seleção, para além do recorte nas duas seções temáticas, foram avaliados os títulos e os resumos das comunicações relativas ao estágio. A leitura de outras partes dos trabalhos ocorreu quando persistiu alguma dúvida levantada sobre a temática.

Após essas análises, separou-se alguns dados gerais, como: localização regional do trabalho, universidade de origem do autor, frequência por localidade e instituição, os quais também embasaram outras análises. A maior parte dos trabalhos referia-se às possibilidades formativas e aos contextos diversos que os estágios representavam.

As autoras apontam para um aumento significativo no número de trabalhos sobre o estágio, se comparada a produção nos anos de 2009 e 2011, haja vista que quase dobrou o número de submissões aceitas que compartilhavam do mesmo objeto. Entretanto, Azevedo e Ferenc (2011) salientam que a produção científica no período coevo acerca do estágio não acompanhou este indicativo presente no CEPFE.

As autoras apontam na Tabela 1 , as instituições de ensino nas quais os comunicadores eram vinculados.

Tabela 1 - Estados e Instituições de origem dos trabalhos e sua frequência. 


\begin{tabular}{lllc}
\hline \multicolumn{1}{c}{ Estado } & \multicolumn{1}{c}{ Instituição/Órgão } & Frequência \\
\hline Amazonas & Universidade Estadual do Amazonas & UEA & 1 \\
Bahia & Universidade Estadual do Sudoeste da Bahia & UNESB & 1 \\
\multirow{2}{*}{ Goiás } & Universidade Estadual de Santa Cruz & UESC & 1 \\
& Universidade Federal de Goiás & UFG & 1 \\
Mato Grosso & Universidade Federal do Mato Grosso & UFMT & 2 \\
Paraná & Universidade Estadual de Londrina & UEL & 2 \\
Piauí & Universidade Estadual do Piauí & UESPI & 1 \\
São Paulo & Secretaria Estadual de Educação & SEE & 1 \\
& Secretaria Municipal de Educação & SME & 1 \\
& Universidade Federal de São Carlos & UFSCar & 3 \\
& Universidade Estadual Paulista & UNESP & 12 \\
& Centro Universitário Central Paulista & UNICEP & 1 \\
& Universidade São Francisco & USF & 1 \\
& Universidade de São Paulo & USP & 3 \\
\hline Total de trabalhos & & $31^{*}$ \\
\hline
\end{tabular}

Fonte: Elaborada pelos autores. Dados do livro eletrônico e do CD-ROM dos eventos (CEPFE, 2009; 2011).

* Ao somarmos os trabalhos apresentados na Tabela 1 nos deparamos com um total de 31 publicações e não de 26 (como traz o texto); esse fato ocorre devido a 5 publicações terem sido realizadas em parceria.

Azevedo e Ferenc (2011) ponderam que a maior parte dos trabalhos é oriunda de instituições da região Sudeste e que na UNESP concentrara quase metade das comunicações. Tal recorrência talvez se deva à localização geográfica do evento e à universidade que o sedia, o que poderia propiciar maior mobilidade entre as instituições localizadas nessa região do país.

As autoras ainda destacam que o aparecimento de órgãos como as Secretarias de Educação, Estadual e Municipal, em parceria com as universidades, se refere, de forma mais incisiva, ao local de trabalho dos pesquisadores e parcerias pessoais, ao contrário de alguma relação de projeto ou de consultoria entre elas. Exceto em um caso específico que se tratava de um projeto para a iniciação à docência.

Todos os trabalhos do X e XI CEPFE selecionados foram de instituições públicas, sendo a maioria dos autores composta de docentes e as pesquisas se referiam a contextos do estágio como disciplina acadêmica. 
Em decorrência dos dados dos artigos apresentados na Tabela 1, outros elementos são explorados, como pode ser visto na Tabela 2.

Tabela 2 - Licenciaturas em que os estágios são pesquisados e sua frequência.

\begin{tabular}{lc}
\hline Licenciaturas & Frequência \\
\hline Ciências Biológicas & 1 \\
Educação Física & 3 \\
Geografia & 1 \\
Letras & 1 \\
Matemática & 6 \\
Normal Superior & 1 \\
Pedagogia & 12 \\
Química & 1 \\
\hline
\end{tabular}

Fonte: Elaborada pelos autores. Dados do livro eletrônico e do CD-ROM dos eventos (CEPFE, 2009; 2011).

Relativo à Tabela 2, a maior concentração dos trabalhos se encontra na área da Pedagogia, partindo de reflexões sobre a docência, suas relações com os espaços escolares, suas dinâmicas e seus contextos para a formação do futuro professor.

As áreas de Matemática e Educação Física foram as que seguiram com maior recorrência, após a Pedagogia. As duas primeiras citadas abordam em seus trabalhos, principalmente, as relações pedagógicas entre suas áreas, evidenciando o papel do estágio como espaço para a formação do educador e local para aprender e pensar em métodos e técnicas para ensinar questões próprias de suas ciências. Outras áreas como: Ciências Biológicas, Geografia, Letras, Normal Superior e Química, localizaram, em menor quantidade, estudos sobre o estágio.

A partir da análise do XII CEPFE em diante, ocorrido em 2014, percebe-se uma reorganização dos eixos temáticos, em comparação ao evento anterior. Portanto, o eixo pesquisado foi o de número 1 , denominado "Políticas e Práticas de formação inicial de professores da educação básica". Os termos de busca e avaliação dos trabalhos tiveram a intenção de manter a simetria em relação ao trabalho realizado por Azevedo e Ferenc (2011). Entretanto, como já salientara Romanowski e Ens (2006), a partir da organização e divulgação dos dados pelos promotores do evento em questão, alguns elementos são evidenciados ou nublados, cabendo ao pesquisador equacionar tais situações. Sendo assim, em um universo de 281 trabalhos no eixo 1, 31 
foram selecionados em função da sua pertinência com o tema. Eles são oriundos de diversas instituições, como se pode ver na Tabela 3.

Tabela 3 - Estados e Instituições de origem dos trabalhos e sua frequência.

\begin{tabular}{|c|c|c|c|}
\hline Estado & Instituição/Órgão & & Frequência \\
\hline Acre & Universidade Federal do Acre & UFAC & 1 \\
\hline Bahia & $\begin{array}{l}\text { Universidade Estadual de Santa Cruz- } \\
\text { Bahia }\end{array}$ & UESC & 1 \\
\hline Maranhão & Universidade Federal do Maranhão & UFMA & 1 \\
\hline \multirow[t]{3}{*}{ Minas Gerais } & Universidade Federal de Viçosa & UFV & 1 \\
\hline & Universidade Federal de Lavras & UFLA & 1 \\
\hline & $\begin{array}{l}\text { Universidade Federal de São João Del- } \\
\text { Rei }\end{array}$ & UFSJ & 1 \\
\hline Paraná & Universidade Estadual de Londrina & UEL & 2 \\
\hline Paraná & Universidade Federal do Paraná & UFPR & 1 \\
\hline Piauí & Universidade Federal do Piauí & UFPI & 1 \\
\hline Rio de Janeiro & Universidade Estácio de Sá & ESTÁCIO & 1 \\
\hline Rio de Janeiro & Universidade Federal do Rio de Janeiro & UFRJ & 3 \\
\hline \multirow[t]{8}{*}{ São Paulo } & Universidade Metodista Mackenzie & MACKENZIE & 1 \\
\hline & Universidade Estadual de Campinas & UNICAMP & 2 \\
\hline & Universidade Federal de São Carlos & UFSCar & 1 \\
\hline & Universidade Estadual Paulista & UNESP & 5 \\
\hline & Universidade Federal de São Paulo & UNIFESP & 1 \\
\hline & Universidade de São Paulo & USP & 5 \\
\hline & Universidade Metodista Paulista & UNIMEP & 1 \\
\hline & $\begin{array}{l}\text { Secretaria de Estado de Educação de } \\
\text { São Paulo. }\end{array}$ & SEE & 1 \\
\hline
\end{tabular}

Fonte: Elaborada pelos autores. Dados dos Anais do XII CEPFE (2014).

A maioria dos trabalhos registrados ainda se concentra na região Sudeste. Em termos numéricos, esta concentração, bem como o quantitativo de instituições de outras regiões, é muito próximo. Julga-se tais condições serem as mesmas que já foram citadas. Apesar de um quantitativo igual ao da USP, a UNESP continuou como a instituição que mais inscreveu trabalhos. A Secretaria de Estado de Educação de São Paulo marca presença no evento em condição análoga a supracitada: em virtude da 
instituição de trabalho do pesquisador. Diferentemente que analisado por Azevedo e Ferenc (2011), as universidades particulares aparecem com trabalhos nos eventos.

A partir da tabela 4, o predomínio da Pedagogia sobre outros campos do conhecimento é visto sem sombra de dúvida. Logo em seguida, as áreas de Ciências Biológicas e Educação Física seguem. Os padrões temáticos dos trabalhos seguem os anteriores: as implicações formativas, teóricas e práticas para os pedagogos e espaço para introdução à docência e busca por métodos de ensino para as disciplinas, no caso dos professores de ciências/biologia e educação física. Outras áreas aparecem com menor número de produções. Ressalta-se aqui que, um curso de enfermagem, está presente na tabela, por ter apresentado um trabalho refletindo a formação do enfermeiro através do estágio.

Tabela 4 - Licenciaturas em que os estágios são pesquisados e sua frequência.

\begin{tabular}{lc}
\hline Licenciaturas & Frequência \\
\hline Ciências Biológicas & 4 \\
Educação Física & 4 \\
Enfermagem & 1 \\
Física & 1 \\
Geografia & 1 \\
Letras & 1 \\
Matemática & 1 \\
Pedagogia & 18 \\
\hline
\end{tabular}

Fonte: Elaborada pelos autores. Dados dos Anais do XII CEPFE (2014).

Em termos metodológicos, foram registrados 18 relatos de experiência e 13 comunicações de pesquisa, que são classificações inscritas no evento. Em linhas gerais, todos os casos se referem diretamente ao ensino superior, com exceção do apresentado pela Secretaria de Estado de Educação. Portanto, a grande parte dos trabalhos é composta por discentes e docentes de cursos de graduação e pósgraduação, e relata episódios de seus estágios e atividades em disciplinas, quando relato de experiência e trechos de pesquisas em andamento ou finalizadas, quando foram comunicações. Apesar da presença constante de professores universitários, o número de discentes é mais significativo quando pensado o XI CEPFE. 
O XIII CEPFE, em 2016, contou com 26 trabalhos selecionados, dentro de um rol de 214. As instituições que trataram do estágio supervisionado na formação inicial de professores podem ser vistas na Tabela 5, a seguir.

Tabela 5 - Estados e Instituições de origem dos trabalhos e sua frequência.

\begin{tabular}{lllc}
\hline Estado & \multicolumn{1}{c}{ Instituição/Órgão } & Frequência \\
\hline Amazonas & Universidade Estadual do Amazonas & UEA & 1 \\
& Universidade Federal do Amazonas & UFAM & 1 \\
Maranhão & Universidade Federal do Maranhão & UFMA & 2 \\
Minas Gerais & Universidade Federal de Viçosa & UFV & 2 \\
Pará & Universidade Federal do Pará & UFPA & 1 \\
& Universidade Federal do Oeste do Pará & UFOPA & 1 \\
Paraná & Universidade Estadual de Ponta Grossa & UFPG & 3 \\
Piauí & Universidade Estadual do Piauí & UESPI & 1 \\
São Paulo & Universidade Metodista Mackenzie & MACKENZIE & 1 \\
& Universidade Estadual de Campinas & UNICAMP & 2 \\
& Universidade Federal de São Carlos & UFSCar & 1 \\
& Universidade Estadual Paulista & UNESP & 5 \\
& Universidade Federal de São Paulo & UNIFESP & 1 \\
& Universidade de São Paulo & USP & 3 \\
Tocantins & Universidade Federal do Tocantins & UFT & 1 \\
\hline
\end{tabular}

Fonte: Elaborada pelos autores. Dados dos Anais do XIII CEPFE (2016).

Como evidenciado nos dados anteriores, a concentração de trabalhos oriundos da região Sudeste; a persistência de um menor número de trabalhos de outras regiões do país; e a maior parte dos trabalhos apresentados estarem veiculados a UNESP, se mantém, pelas suposições já explicitadas.

Em termos da Tabela 6, apesar de se notar maior diversificação das áreas as quais o estágio é citado, a Pedagogia continua como principal produtora de trabalhos na área, em um viés já contextualizado. Nota-se uma tímida diminuição quando se compara o XII com o XIII CEPFE e esta minoração será mais forte no XIV.

Os anais disponibilizados que tivemos acesso, não organizaram pela divisão entre relato de experiência e comunicação de pesquisa, apesar de tal separar continuar vigente. Entretanto, a despeito disto, o padrão sentido no XII Congresso pode ser percebido no XIII. 
Tabela 6 - Licenciaturas em que os estágios são pesquisados e sua frequência.

\begin{tabular}{lc}
\hline Licenciaturas & Frequência \\
\hline Arte & 1 \\
Ciências Biológicas & 3 \\
Educação Física & 2 \\
Física & 1 \\
Geografia & 1 \\
Letras & 2 \\
Matemática & 2 \\
Música & 1 \\
Pedagogia & 12 \\
Sociologia & 1 \\
\hline
\end{tabular}

Fonte: Elaborada pelos autores. Dados dos Anais do XIII CEPFE (2016).

Já no XIV CEPFE ocorrido em 2018, foram inscritos para o eixo 1, 186 trabalhos. Apenas 11 tocavam na temática do estágio. As instituições universitárias que eles se vinculavam podem ser visualizadas, a seguir, na Tabela 7.

Tabela 7 - Estados e Instituições de origem dos trabalhos e sua frequência

\begin{tabular}{lllc}
\hline Estado & \multicolumn{1}{c}{ Instituição/Órgão } & Frequência \\
\hline Goiás & Universidade Federal de Goiás & UFG & 1 \\
Mato Grosso & Universidade Estadual de Mato Grosso & UNEMAT & 1 \\
\cline { 2 - 2 } & Universidade Federal da Paraíba & UFPB & 1 \\
Paraná & Universidade Estadual de Ponta Grossa & UFPG & 2 \\
Piauí & Universidade Estadual do Piauí & UESPI & 1 \\
São Paulo & Universidade Estadual Paulista & UNESP & 2 \\
& Universidade de São Paulo & USP & 1 \\
& Instituto Federal de Educação, Ciência e & & 1 \\
& Tecnologia de São Paulo & IFESP & 1 \\
\hline
\end{tabular}

Fonte: Elaborada pelos autores. Dados dos Anais do XIV CEPFE (2018).

A concentração de trabalhos na região Sudeste é uma constante. Apesar do número de trabalhos da UNESP ter diminuído e se equiparado com o de outras instituições, ela ainda continuou com destaque na área.

Na Tabela 8, o panorama se repetiu ao da primeira exposição dos dados do X e do XI CEPFE, em menor proporção. Devido a uma diminuição significativa entre o XII e 
o XIV congressos, já citada, percebe-se que apesar da Pedagogia e da Matemática, virem respectivamente como mais citadas, eles registram 4 e 2 trabalhos.

Tabela 8 - Licenciaturas em que os estágios são pesquisados e sua frequência

\begin{tabular}{lc}
\hline Licenciaturas & Frequência \\
\hline Ciências Biológicas & 1 \\
Educação Física & 1 \\
Física & 1 \\
Letras & 1 \\
Matemática & 2 \\
Pedagogia & 4 \\
\hline
\end{tabular}

Fonte: Elaborada pelos autores. Dados dos Anais do XIV CEPFE (2018).

Em termos de análise dos conteúdos, pode-se perceber uma equivalência temática que já vinha sido explicitada. Já em termos metodológicos, foram 5 relatos de experiência e 5 comunicações de pesquisa, que conferem as implicações de organizações do texto supracitadas.

Destarte, quando refletimos em longa duração, percebemos que os locais de produção, as instituições e o campo de atuação permanecem, em sua grande parte, inalteradas, frente a pequenas alterações de cada Congresso.

\section{Considerações Finais}

O presente trabalho evidencia que a temática do estágio na formação inicial está presente nos debates acadêmicos, o que realça, para além de toda a produção acerca da formação inicial docente e o estágio, a necessidade de uma prática contínua de investigações, análises e de avaliações.

De forma bastante sintética, apontaremos alguns dados gerais acerca do estágio, sinalizados nos trabalhos. Em âmbito mais ampliado, percebe-se que no decorrer dos Congressos analisados, persistem, com cores locais distintas, demandas muito próximas.

As relações entre teoria-prática, a reflexão na atuação docente, são temas bastantes debatidos na área da Pedagogia.

O espaço da escola também foi bastante debatido. Ora como espaço central da formação dos futuros professores, considerando-a como elo entre os saberes acadêmicos e a realidade, o contexto dos educandos e da comunidade. 
Percebe-se que nas outras áreas de conhecimento citadas, o estágio é entendido como momento para se pensar sobre as práticas e como ensinar determinados temas daquele conteúdo. Com o decorrer das discussões pelos Congressos, sente-se a transformação das ideias acerca da escola e do papel do professor: cada vez mais é preconizado o professor pesquisador e que, portanto, entende a escola como lócus de suas reflexões e espaço a ser construído e questionado.

Como as experiências acerca das disciplinas práticas e do próprio estágio foram objetos de estudo, bem como suas configurações teóricas e sua presença/ausência nos cursos de formação, vários desafios e possibilidades foram postos. Desde questões curriculares e dos entendimentos de formação e estágio apregoados nos cursos, até sobre práticas e possibilidades de relações entre os agentes dos espaços formadores. Entretanto, o estágio se configura como um ponto pacífico da importância do estágio na configuração das aproximações entre os licenciandos e o futuro espaço de trabalho.

Entende-se o espaço formativo do estágio como interlocutor entre teoria e prática, produtor de pesquisa e essencial para que o estudante sinta um pouco da complexidade sobre o que a profissão docente oferece.

Destarte, com tal mapeamento, é possível identificar demandas sensíveis das produções e de temáticas sobre o estágio na formação inicial que oportuniza uma série de posturas formativas para o futuro professor.

Em suma, a análise dos trabalhos e o aporte da literatura nos permitiu pensar que vivemos, em contexto nacional e internacional, um momento de discussão sobre o papel da escola nas sociedades e isso impõe aos cursos de formação inicial de professores uma autoanálise e avaliação. Entendemos que o estágio pode ser um esse espaço profícuo de debates, diálogos e de mediação entre contextos, saberes e sujeitos de aprendizagem.

\section{Referências}

AMBROSETTI, N. B.; RIBEIRO, M. T. M. A escola como espaço de trabalho e formação dos professores. In: CONGRESSO ESTADUAL PAULISTA SOBRE FORMAÇÃO DE EDUCADORES, 8., 2005, São Paulo. Anais [...]. São Paulo: UNESP, 2005. 
AZEVEDO, C. L.; FERENC, A. V. F. O estágio curricular na formação inicial de professores: análise dos textos do X e XI Congresso Estadual Paulista sobre Formação de Educadores. 2012. 27 p. Trabalho de conclusão de curso (Licenciatura em Pedagogia) - Universidade Federal de Viçosa, Viçosa, Minas Gerais, 2012.

AZEVEDO, C. L.; FERENC, A. V. F. SOUZA, F. M. G. de. Diálogos sobre formação de professores: a produção do GT 8 da 33a Reunião da ANPEd. In: SIMPÓSIO DE INTEGRAÇÃO ACADÊMICA, UFV, 2011. Anais [...]. Viçosa: UFV, 2011.

CANÁRIO, R. O papel da prática profissional na formação inicial e contínua de professores. In: CONGRESSO BRASILEIRO DE QUALIDADE NA EDUCAÇÃO, 10., 2002, Brasília. Anais [...]. Brasília: MEC, 2002.

CONGRESSO ESTADUAL PAULISTA SOBRE FORMAÇÃO DE EDUCADORES, 10., 2009, Águas de Lindóia. Anais [...]. Águas de Lindóia: UNESP, 2009. Disponível em: http://unesp.br/prograd//conteudo.php?conteudo=1622\&direto=S. Acesso em: 1 set. 2020.

CONGRESSO ESTADUAL PAULISTA SOBRE FORMAÇÃO DE EDUCADORES, 11., 2011, Águas de Lindóia. Anais [...]. Águas de Lindóia: UNESP, 2011. 1 CD-ROM.

CONGRESSO ESTADUAL PAULISTA SOBRE FORMAÇÃO DE EDUCADORES, 12., 2014, Águas de Lindóia. Anais [...]. Águas de Lindóia: UNESP, 2014. Disponível em: https://www.geci.ibilce.unesp.br/logica_de_aplicacao/site/index_1.jsp?id_evento=31 . Acesso em: 22 set. 2020.

CONGRESSO ESTADUAL PAULISTA SOBRE FORMAÇÃO DE EDUCADORES, 13., 2016, Águas de Lindóia. Anais [...]. Águas de Lindóia: UNESP, 2016.

CONGRESSO ESTADUAL PAULISTA SOBRE FORMAÇÃO DE EDUCADORES, 14., 2018, Águas de Lindóia. Anais [...]. Águas de Lindóia: UNESP, 2018.

DAMASCENO, K. K.; MONTEIRO, F. M. A. Formação continuada: uma contribuição para a construção de conhecimentos necessários à prática docente. In: CONGRESSO ESTADUAL PAULISTA SOBRE FORMAÇÃO DE EDUCADORES, 8., 2005, São Paulo. Anais [...]. São Paulo: UNESP, 2005.

GARCIA, C. M. Formação de professores: para uma mudança educativa. Portugal: Porto Editora, 1999.

IMBERNÓN, F. Formação docente e profissional: formar-se para a mudança e a incerteza. 9. ed. São Paulo: Cortez, 2011. (Coleção Questão de nossa época). 
NOGUEIRA, B. S. Necessidades docentes de formação. In: CONGRESSO ESTADUAL PAULISTA SOBRE FORMAÇÃO DE EDUCADORES, 8., 2005, São Paulo. Anais [...]. São Paulo: UNESP, 2005.

NÓVOA, A. Os professores e a sua formação num tempo de metamorfose da escola. Educação \& Realidade, Porto Alegre, v. 44, n. 3, p. 1-15, 2019. Disponível em: https://www.scielo.br/scielo.php?pid=S2175-

62362019000300402\&script=sci_arttext. Acesso em: 14 set. 2020.

NÓVOA, A. Desafios do trabalho do professor no mundo contemporâneo. São Paulo: Sinpro-SP, 2007.

NÓVOA, A. et al. Profissão professor. 2. ed. Portugal: Porto Editora, 1999.

NÓVOA, A. Novas disposições dos professores: a escola como lugar da formação, Lisboa: Universidade de Lisboa, 2003.

NÓVOA, A. Para uma formação de professores construída dentro da profissão. In: NÓVOA, A. Professores: imagens do futuro presente. Lisboa: Educa, 2009.

OLIVEIRA, M. R. G.; FREITAS, D. Parceria entre universidade e escola pública: uma possibilidade de desenvolvimento profissional. In: CONGRESSO ESTADUAL PAULISTA SOBRE FORMAÇÃO DE EDUCADORES, 8., 2005, São Paulo. Anais [...]. São Paulo: UNESP, 2005.

PIMENTA, J. I. P. B.; CHRISTENSEN, J. E.; RINALDI, E. C.; Investigação das necessidades formativas: a busca de estratégias adequadas de formação continuada de professores. (FCL/UNESP/Araraquara). In: CONGRESSO ESTADUAL PAULISTA SOBRE FORMAÇÃO DE EDUCADORES, 8., 2005, São Paulo. Anais [...]. São Paulo: UNESP, 2005.

PIMENTA, S. G.; LIMA, M. S. L. Estágio e docência. São Paulo: Cortez, 2004.

ROMANOWSKI, J. P.; ENS, R. T. As pesquisas denominadas do tipo "estado da arte" em educação. Revista Diálogo Educacional [online], v. 6, n. 19, p. 37-50, 2006. Disponível em: http://redalyc.uaemex.mx/redalyc/pdf/1891/189116275004.pdf. Acesso em: 05 dez. 2019.

Enviado em: $22 / 04 / 2020$

Aprovado em: 21/10/2020 